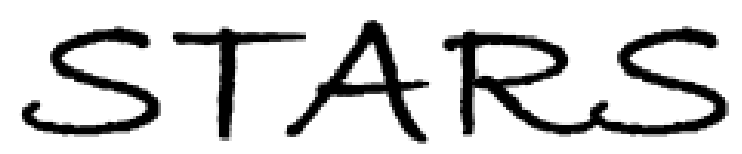

University of Central Florida

STARS

Retrospective Theses and Dissertations

1986

\title{
Optimizing scanning mirror system performance using solid state piezoelectric actuators
}

Thomas J. Tomasetti

University of Central Florida

Part of the Engineering Commons

Find similar works at: https://stars.library.ucf.edu/rtd

University of Central Florida Libraries http://library.ucf.edu

This Masters Thesis (Open Access) is brought to you for free and open access by STARS. It has been accepted for inclusion in Retrospective Theses and Dissertations by an authorized administrator of STARS. For more information, please contact STARS@ucf.edu.

\section{STARS Citation}

Tomasetti, Thomas J., "Optimizing scanning mirror system performance using solid state piezoelectric actuators" (1986). Retrospective Theses and Dissertations. 4981.

https://stars.library.ucf.edu/rtd/4981

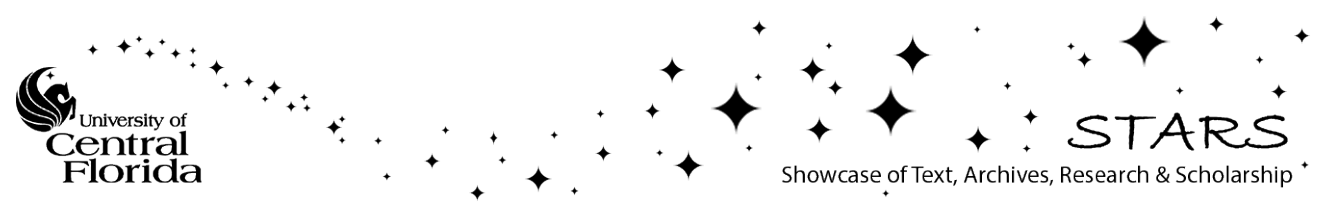


OPTIMIZING SCANNING MIRROR SYSTEM PERFORMANCE USING SOLID STATE PIEZOELECTRIC ACTUATORS

\author{
BY \\ THOMAS $\mathrm{J}$ TOMASETTI \\ B.S.E., University of Central Florida, 1984
}

THESIS

Submitted in partial fulfillment of the requirements for the degree of Master of Science in Engineering in the Graduate Studies Program of the College of Engineering University of Central Florida orlando, Florida

Fall Term 1986 


\section{ABSTRACT}

The purpose of this thesis is to design a scanning mirror system using piezoelectric actuators. A dual-cantilevered bimorph electromechanical coupling is presented, which maximizes the amount of angular deflection possible with an applied field. Two types of feedback methods are employed: rate sensing, which provides resonance damping, anc position sensing for increased bandwidth and decreased hysteresis. A prototype system, including the actuator and feedback mechanisms, is developed. Its performance compares favorably with its model and is capable of plus and minus five degrees of angular deflection with a bandwidth of 300 Hertz. 


\section{TABLE OF CONTENTS}

List of Figures... . . . . . . . . . . . . . iv List of symbols... . . . . . . . . . . . . v Introduction .............. . . . . 1 Ceramic Piezoelectrics . . . . . . . . . . 3 Piezoelectric Actuators . . . . . . . . . . . 7 Subsystem Models . . . . . . . . . . . . . . . 11 System Synthesis and Analysis . . . . . . . . . 28 Conclusions . . . . . . . . . . . . . . . 38 Summary . . . . . . . . . . . . . . 4 41 References ................. . . 43 
LIST OF FIGURES

1. Pusher ................... 4

2. Monomorph ................. . 5

3. Bimorph ... . . . . . . . . . . . 6

4. Actuator . . . . . . . . . . . . . 9

5. Transverse Loaded Beam . . . . . . . . . . 11

6. Model Schematic ........... .... 13

7. Actuator Impedance . . . . . . . . . . . 14

8. Higher Order Model Schematic . . . . . . . . 17

9. Amplifier Schematic . . . . . . . . . 20

10. Low Pass Filter .. . . . . . . . . . . 23

11. Rate Feedback Electronics .......... . 23

12. Colpitts oscillator . . . . . . . . . . 26

13. Load Lines... . . . . . . . . . . . . 27

14. Position Feedback Schematic . . . . . . . . 27

15. Block Diagram ............... 29

16. Actuator Response . . . . . . . . . . . . 31

17. Updated Actuator Response . . . . . . . . . 31

18. Biquad Notch Filter ............ . 33

19. Control Schematic . . . . . . . . . . . 35

20. System Block Diagram ............. . 36

21. Open Position Loop Response . . . . . . . . . 36

22. Closed Position Loop Response . . . . . . . . 37 


\section{LIST OF SYMBOLS}

$\mathrm{A}_{\mathrm{CL}} \quad$ Closed Loop Transfer Function

AOL Open Loop Transfer Function

B Difference of Two Bandpass Cutoff Frequencies

$\mathrm{C}_{\mathrm{e}} \quad$ Electrical Capacitance

$\mathrm{C}_{\mathrm{m}} \quad$ Mechanical Capacitance

$\mathrm{C}_{\mathrm{h}} \quad$ Higher order Mechanical Capacitance

$\mathrm{C}_{\mathrm{T}} \quad$ Low Frequency Capacitance

$\mathrm{D}_{31}$ Bender Piezoelectric Constant

$D_{33} \quad$ Pusher Piezoelectric Constant

E Modulus of Elasticity

$\mathrm{H}_{\mathrm{a}} \quad$ Actuator Displacement Transfer Function

$\mathrm{H}_{\mathrm{C}} \quad$ Compensator Transfer Function

$\mathrm{H}_{\mathrm{CR}}$ Closed Rate Loop Transfer Function

$\mathrm{H}_{\mathrm{LP}} \quad$ Rate Loop Low Pass Filter Transfer Function

$\mathrm{H}_{\mathrm{R}} \quad$ Open Rate Loop Transfer Function

I Moment of Inertia

$\mathrm{K}_{\theta} \quad$ Actuator Angular Displacement Scale Factor

$\mathrm{K}_{\mathrm{pd}} \quad$ Position Detector Scale Factor

$\mathrm{L}_{\mathrm{m}} \quad$ Mechanical Inductance

$\mathrm{L}_{\mathrm{h}} \quad \mathrm{Higher}$ order Mechanical Inductance

P Loading Force

QP Parallel Resonance Quality Factor

$Q_{S} \quad$ Series Resonance Quality Factor 


$\begin{array}{ll}R_{m} & \text { Mechanical Resistance } \\ R_{h} & \text { Higher Order Mechanical Resistance } \\ S & \text { Laplace Transform Operator } \\ W_{p} & \text { Parallel Resonance Frequency } \\ W_{S} & \text { Series Resonance Frequency } \\ X & \text { Direction } \\ Y & \text { Direction } \\ Y & \text { Actuator Transfer Admittance } \\ Y^{\prime} & \text { Modified Transfer Admittance } \\ Y_{R L C} & \text { Acimittance of RLC Series Element } \\ Z & \text { Actuator Input Impedance } \\ B & \text { Feedback Gain } \\ \sigma & \text { Stress }\end{array}$




\section{INTRODUCTION}

Scanning mirrors are one of the most popular control elements used in electro-optical systems. Their applications include the autocorrection of a laser path over time and temperature, target tracking and designation, and image scanning of a specific field of view. These applications suggest wide varieties of motion, from slow anc ultraprecise to wide angle and finally high speed. When considering an actuator for the scanning mirror system, its operating frequency spectrum and electro-mechanical interface, along with power efficiency, workability and cost criteria, should indicate feasibility.

The term solid state implies a mechanism with no moving surface interfaces. This "buzzword" received its notoriety when transistors and other such devices were used to control current in power circuits rather than electromagnetic relays and vacuum tubes. In the same way, a solid state actuator is a mechanism which provides motion without separate pulleys, gears and shafts; a solid object capable of producing motion! Since there are no surfaces to wear out, solid state actuators are rugged and dependable, providing benefits in cost and reliability of performance.

Piezoelectric material is one which posesses many of the actuator qualities desired. This material produces an 
electric potential with applied stress or deforms with applied potential. The linear nature of this piezoelectric effect suggests its dual purpose of acting as both an actuator and a sensor, which can be useful for control. Also, piezoelectric devices are used over a wide range of frequencies, from transducers in the audio range to surface acoustic wave (SAW) devices operating up to one gigahertz. Finally, in the subset of ceramic piezoelectrics, the material is easily workable, relatively inexpensive and highly capacitive, suggesting it to be an energy storage element and therefore power efficient.

The purpose of this research is to present the feasibility of scanning mirror piezoelectric actuators by designing, building and testing an actual scanning mirror system. In this paper, ceramic piezoelectrics will be reviewed. The advantages and difficulties associated with piezoactuators will be discussed, and the proposed scanning mirror system will be introduced. Next, models will be developed for the actuator, drive amplifier and feedback sensors. Once these individual parts have been defined, the entire system will be analyzed with respect to a set of sample specifications. Finally, the performance of the actual prototype will be compared to that of the model. 
CERAMIC PIEZOELECTRICS

Ceramic piezoelectric transducers cover a wide variety of applications from microphones and hydrophones, to electro-optic modulators and micropositioners Ceramic material not only posesses strong piezoelectric tendencies, but it can be easily molded into almost any desired shape. Manufacturers' stock items usually include plates, cylinders, bars and discs. The ceramic material used is a holocrystalline compound such as barium titanate and lead titanate zirconate. Many of the popular transducers use these compounds formulated for the intended application. One such formulation used for its high sensitivity and permittivity is known as PZT-5H. [4]

In the beginning of the manufacturing process, the material is molded into the shape desired. Once it has dried, it is then heated to vitrify the surface of the ceramic, making it brittle. Electrodes can then be attached by electroplating or vacuum deposition methods, or they can be bonded with conductive epoxy. Finally, the transducer is heated to the Curie temperature so that the molecules are somewhat free to move, and a large voltage is applied. The dipoles align along the applied field after a time, and the material is cooled, restricting the molecules to the alignment desired. Thus the transducer's electromechanical 
qualities are established. The direction of polarization can be varied, producing two major types of ceramic transducers, "pushers" and "benders."[6]

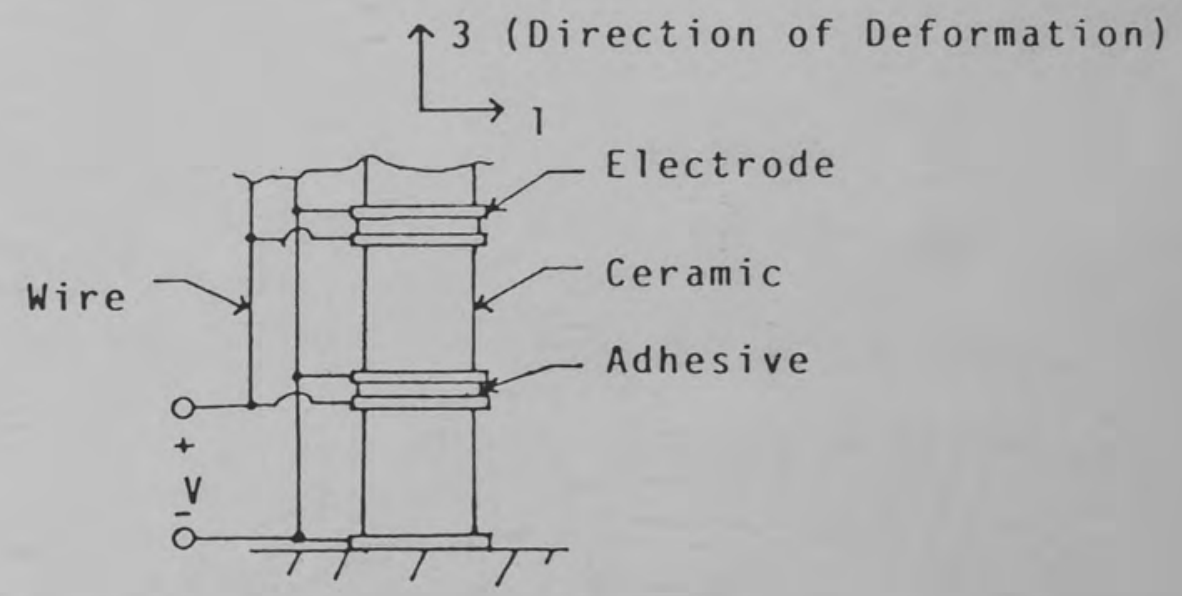

Figure 1. Pusher

When the transducer is polarized such that the direction of the strain generated with applied potential is parallel to the cross sectional area normal, the result is known as a pusher. The produced motion is a direct result of the strain or elongation. The motion sensitivity of the ceramic is given as the piezoelectric constant

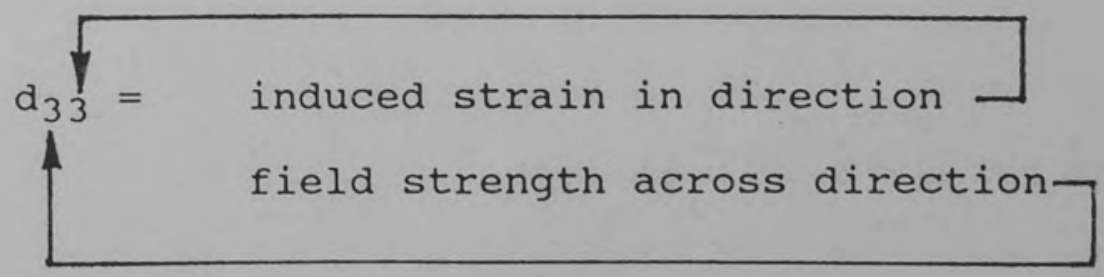

and is approximately $500 \mathrm{E}-12$ meters/volt. The usual method for increasing the sensitivity of a pusher is to stack as many as 300 of these single elements with the electrodes connected in parallel. The final transducer is a 
micropositioner with displacements up to 60 micrometers with one kilovolt applied, as shown in Figure 1.

When considering basic mechanics, it is remembered that amplified motion is obtained with mechanical advantage, a function missing in the pusher. Benders, on the other hand, use this "moment arm" technique to achieve the sensitivity needed to detect acoustic waves. The polarization for the bender produces strain perpendicular to the area normal. In the case of a monomorph, the ceramic is bonded to a thin sheet of brass so that the deformation of the ceramic will cause the monomorph to bend. The strain can occur radially causing an "umbrella" bending mode, as in the case of a disc, or longitudinally, as in the long, thin bar of Figure 2. This bending can then be amplified further using two ceramic elements bonded together and connected electrically so that a certain field polarity will cause elongation in one element and contraction in the other. The configuration described is the bimorph of Figure 3 . This dual shear

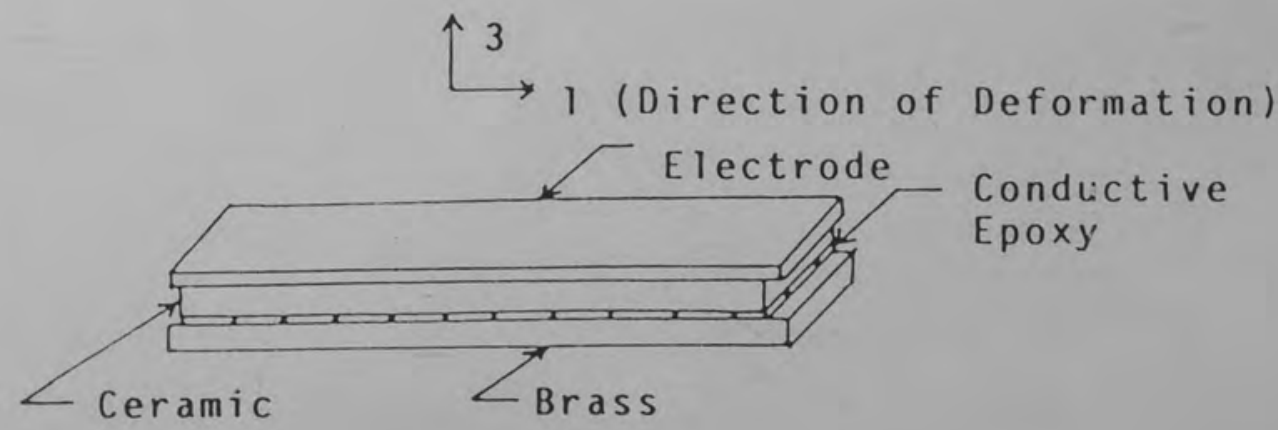

Figure 2. Monomorph 
effect doubles the sensitivity possible with a single monomorph. Although the deformation described by the constant $d_{31}$ is usually half that of $d_{33}$, the motion due to bending is an increase of several orders of magnitude over the pusher, to 2.5 E-6 meters/volt.[10] This increase shows the potential of benders to surpass the more con'entional pusher micropositioners in many applications, including scanning mirror systems.

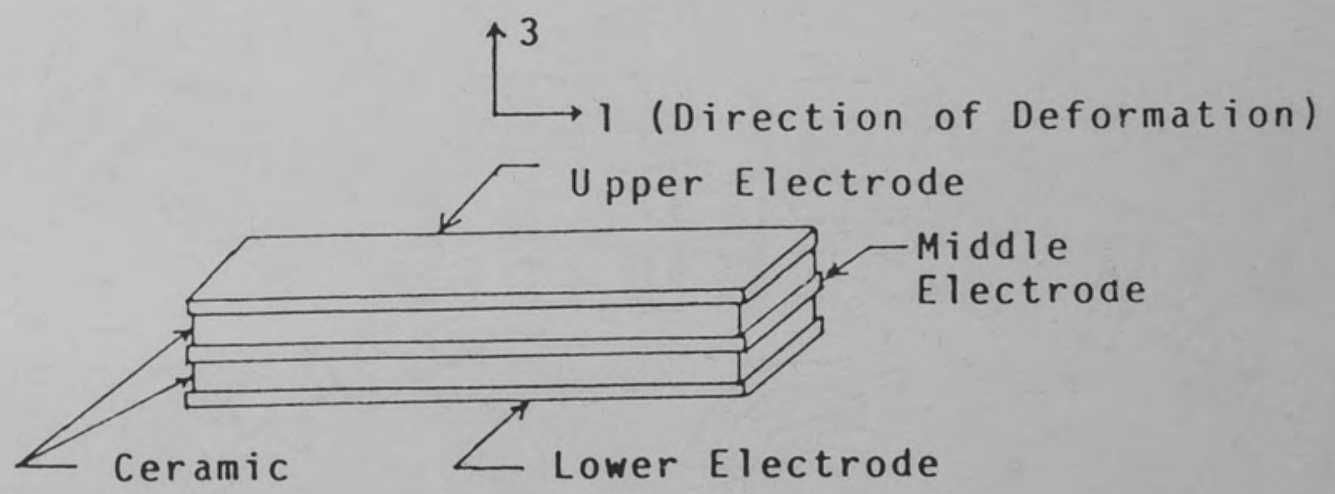

Figure 3. Bimorph 


\section{PIEZOELECTRIC ACTUATORS}

There are many advantages to using a piezoelectric actuator in scanning applications. These become evident when it is compared to its classical counterpart, the motor driven system. One advantage is that the piezoactuator is solid state. No matter how well designed, moving parts such as shafts, gears and bearings wear out. This lowers reliability and operating lifetime.

Another profit is made with respect to electromechanical conversion efficiency. Motor sytem efficiencies are normally 40-60\%, whereas piezoelectrics achieve 80-95\%. This means lower power requirements, smaller size and decreased cost. [4]

From a system design perspective, piezoactuators are simpler to work with owing to fewer nonlinearities. Friction, wire torque and backlash are just some of the factors common to motor systems that initiate limit cycling and degrade bandwidth and overall system performance. Although nonlinearities exist in piezoelectrics, their effects are minimal.

These advantages, in addition to a large cost improvement, make piezoactuators seem without flaw. However, there are some drawbacks. The major problem is the amount of displacement versus voltage. As previously stated, 
micropositioners currently available move at a slope of 60 micrometers/kilovolt. To convert this small movement into a reasonable angle the pushers must be attached to the mirror as close to each other as possible. This is limited by the size of the actuators and the allowable stress at the mirror-transducer coupling. Employing the mechanical advantage of benders should help to alleviate this matter.

Mechanical resonance is another drawback that must be faced. Due to very low dissipation levels and a large moment arm, resonance can be quite severe. If the mechanism is to be used in a closed loop system, this resonance must be damped to insure stability.

The final problem is the single most nonlinearity associated with piezoelectrics: hysteresis. This is the inability of the transducer to return to its original shape after large displacements when the voltage is reduced to zero. The ceramic composition and configuration, bonding agent and magnitude of applied field determine the amount of hysteresis.

Now that the problem areas have been defined, a system can be proposed that will overcome these difficulties and benefit from the piezoactuator's superior qualities. This system begins with the actuator of Figure 4. This dual cantilever mounted bimorph approach will maximize the amount of angular motion possible. The hinges coupling the mirror to the bimorph allow unrestricted motion of the transducer 
without any stress being placed on the mirror. In the prototype, double-sided adhesive tape is used, since the mirror is small and light. With a heavier mirror, a semirigid adhesive such as silicone could be used as the hinge. The mirror is flat glass, $3 / 4$ of an inch square and 1/8 inch thick. It is attached at its ends to further limit coupling stresses. Larger angular displacements can be achieved as the attachments are moved toward the center of the mirror, as long as the hinge can absorb the stress without bending the mirror.

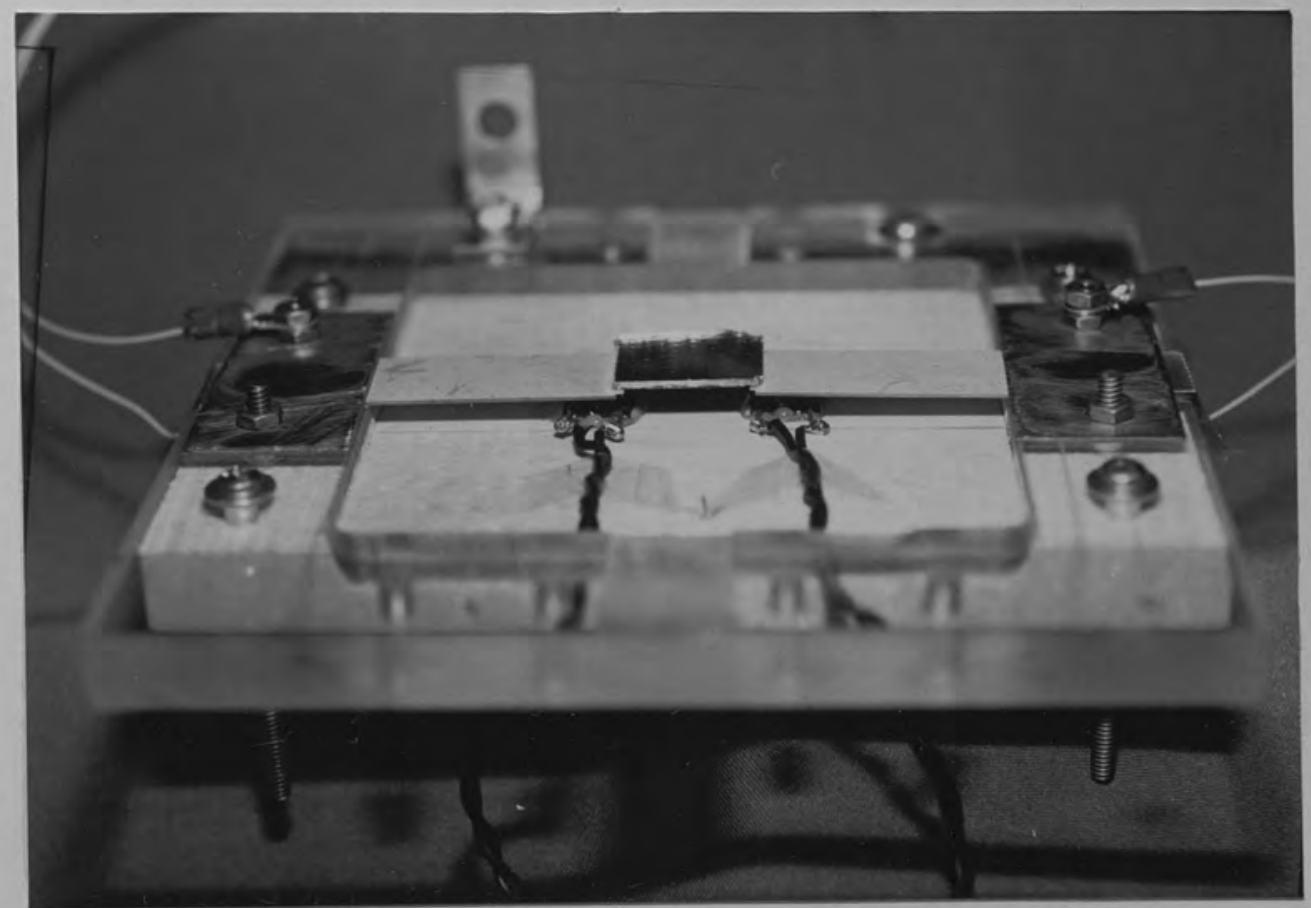

Figure 4. Actuator 
The next part of the scanning mirror system is the drive amplifier. It must be capable of driving high voltage levels into a complex impedance that changes with frequency. High voltage operational amplifiers seem a likely candidate. They are capable of ouputs of $+/-300$ volts with a driving power of 50 watts into both inductive and capacitive loads. However, this large amount of power is not needed in driving the actuator. The voltage swing is the most important capability for the present application. Actually, larger deflections are possible if higher voltage amplifiers are available. The deflection limit is set by the elastic limit of the piezoelectric material.

The system will use two different feedback variables. Rate feedback will be used to damp the resonance. This variable will be obtained from the current through the transducers. The other feedback element will be a position sensor. Position feedback will eliminate hysteresis and extend bandwidth. To avoid any wires or other attachments to the mirror, an Eddy current proximity detector will provide the necessary position information. 


\section{SUBSYSTEM MODELS}

In developing models for each of the four parts of the scanning mirror system, (the actuator, amplifier, rate sensor and position sensor) the purpose is to provide useful system representations. These can exist in different forms each providing distinct pieces of information, yet equivalent to the others. The actual hardware produces the desired function. A schematic diagram not only describes the hardware used and how it is interconnected, but it denotes a set of equations which again delineate the function of the prototype. All of these forms will be used interchangeably in the following discussion.

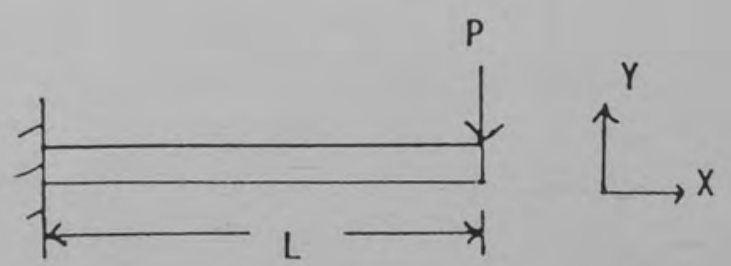

Figure 5. Transverse Loaded Beam

Empirical modeling is a tool which can provide an accurate representation of the main assembly, the mirror actuator. Even though the model is based on measured values, behind it is a theoretical basis. This theory begins with the linear nature of the bending of the cantilever mounted bimorph. The piezoelectric stress 
developed in the long, thin bar can be likened to the transverse loaded beam of Figure 5. This stress is directly proportional to the load or

$$
\sigma \simeq P
$$

Also, the deflection at the edge of the beam follows the relation

$$
Y=\frac{-P L^{3}}{3 E I}
$$

where $L=$ length of beam

$E=$ modulus of elasticity

$I=$ moment of inertia of the cross section with respect to the $\mathrm{x}$ axis

Since the deflection is directly proportional to the loading force or stress, the mirror's angular subtense is linear with respect to applied voltage within elastic limits, as long as that subtense is small. [2]

The next noteworthy point is that the deflection is also linear with respect to charge. This relationship can be observed by applying a voltage to the actuator through a switch and then breaking the switch. The mirror does not move immediately to its original position but remains at the deflected angle. After a long time, it will fade back to its zero position. This phenomenon indicates dissipation or 
resistive losses. The model at this point resembles an RC low pass filter, where the output voltage is proportional to charge and position.

In adding the final touches to the model, it is important to recognize that our mirror assembly is actually a mechanical resonator with both inertance and compliance. These attributes suggest that the first order RC circuit should be replaced with a second order RLC series circuit.

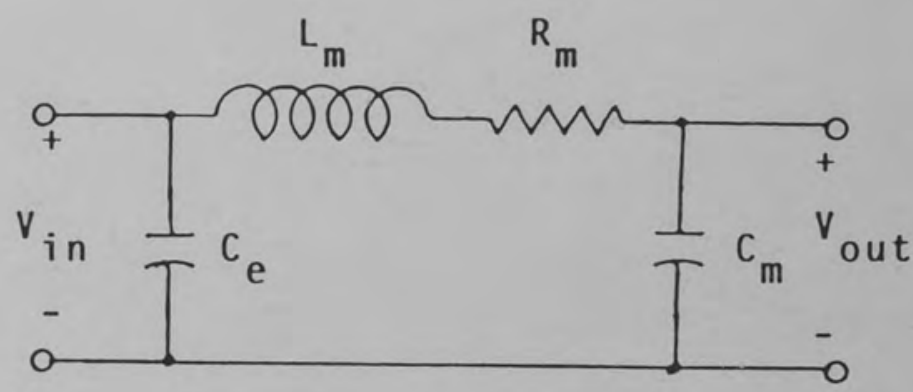

Figure 6. Model Schematic

The last element to be included is the electrical capacitance, a loading effect that can be measured across the electrodes. A schematic of the developed model is given in Figure 6. The two applicable equations (expressed in the Laplace domain) are for input impedance and position versus applied voltage and are:

$$
Z(s)=\frac{L_{m} C_{m} s^{2}+R_{m} C_{m} s+1}{\left(C_{e}+C_{m}\right) s\left[\frac{L_{m} C_{e} C_{m} s^{2}}{\left(C_{e}+C_{m}\right)}+\frac{R_{m} C_{e} C_{m} s+1}{\left(C_{e}+C_{m}\right)}\right]}
$$




$$
H_{\mathrm{a}}(\mathrm{s})=\frac{\mathrm{K}_{\theta}}{\mathrm{L}_{\mathrm{m}} \mathrm{C}_{\mathrm{m}} \mathrm{s}^{2}+\mathrm{R}_{\mathrm{m}} \mathrm{C}_{\mathrm{m}} \mathrm{s}+1}
$$

To complete the actuator model, values for the components must be determined. The method put to task is the same as in passive filter synthesis, equating coefficients. The impedance equation is of the form

$$
z(s)=\frac{\frac{s^{2}}{W_{s}} 2+\frac{s}{Q_{s} W_{s}}+1}{C_{T} s\left[\frac{s^{2}}{W_{p}} 2+\frac{s}{Q_{p} W_{p}}+1\right]}
$$

where $\mathrm{W}_{\mathrm{S}}=$ series resonant frequency

$Q_{\mathrm{S}}=$ series quality factor

$\mathrm{w}_{\mathrm{p}}=$ parallel resonant frequency

$\varrho_{p}=$ parallel quality factor

$\mathrm{C}_{\mathrm{T}}=$ low frequency capacitance

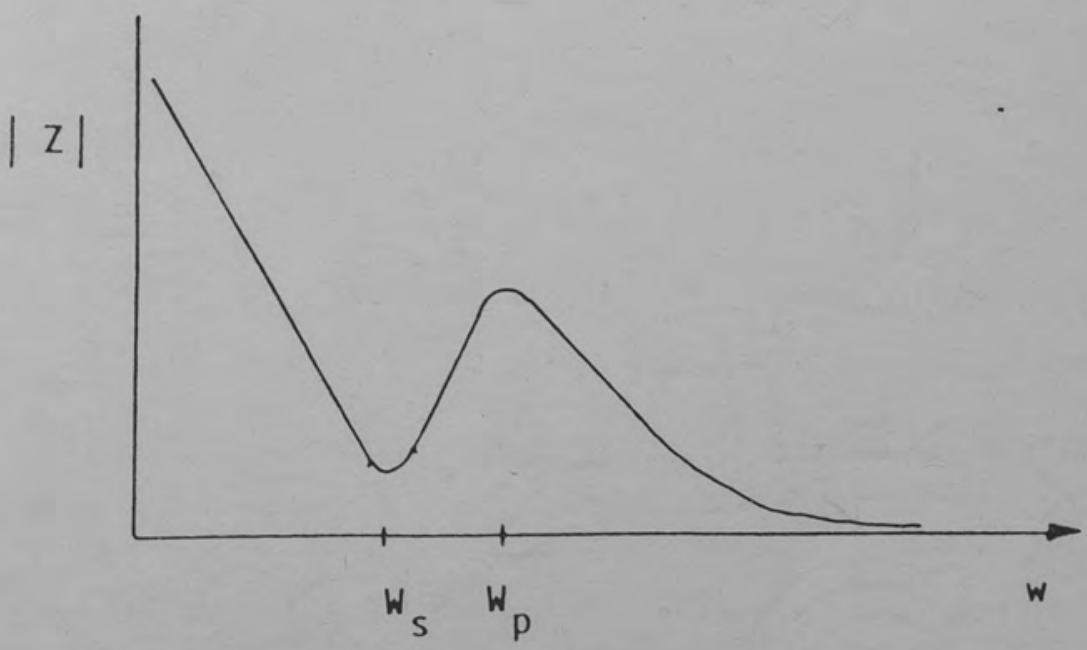

Figure 7. Actuator Impedance 
The procedure for finding the values begins with observing the impedance transform of the mirror actuator assembly on a spectrum analyzer to find the series and parallel resonant frequencies. These are easily located as shown on the magnitude impedance plot of Figure 7 . $Q_{\mathrm{S}}$ was also determined from this plot by the equation

$$
\mathrm{Q}_{\mathrm{S}}=\frac{\mathrm{W}_{\mathrm{S}}}{\mathrm{B}}
$$

where $\mathrm{B}$ is difference of the $3 \mathrm{~dB}$ frequencies on either side of $\mathrm{W}_{\mathrm{S}}$. The other measured value is $\mathrm{C}_{e}$, which can be obtained with a capacitance meter. The values for the prototype are:

$$
\begin{aligned}
& \mathrm{W}_{\mathrm{S}}=1131 \mathrm{rad} / \mathrm{sec} \\
& \mathrm{W}_{\mathrm{p}}=1263 \mathrm{rad} / \mathrm{sec} \\
& \mathrm{Q}_{\mathrm{S}}=8.0 \\
& \mathrm{C}_{\mathrm{e}}=39.4 \mathrm{nF}
\end{aligned}
$$

Equating coefficients yields the relations

$$
\begin{aligned}
& w_{s^{2}}=\frac{1}{L_{m} C_{m}} \\
& w_{p}^{2}=\frac{\left(C_{e}+C_{m}\right)}{L_{m} C_{e} C_{m}}
\end{aligned}
$$

The ratio of these two equations gives the function

$$
c_{m}=c_{e}\left[\frac{w_{p}{ }^{2}}{w_{s}^{2}}-1\right]
$$


The other values are obtained by equating the remaining coefficients and are

$$
\begin{aligned}
& L_{m}=\frac{1}{w_{s}{ }^{2} C_{m}} \\
& R_{m}=\frac{1}{w_{s} Q_{s} C_{m}}
\end{aligned}
$$

Exercising the above equations will yield:

$$
\begin{aligned}
& \mathrm{C}_{\mathrm{e}}=39.4 \mathrm{nF} \\
& \mathrm{C}_{\mathrm{m}}=8.13 \mathrm{nF} \\
& \mathrm{R}_{\mathrm{m}}=13370 \text { ohms } \\
& \mathrm{L}_{\mathrm{m}}=93.0 \mathrm{H}
\end{aligned}
$$

The only value yet to be equated is $\mathrm{K}_{\theta^{\prime}}$ the actuator's electromechanical scale factor. This can be resolved by reflecting a visible high intensity light source (such as a HeNe laser) off of the mirror onto a target. The actuator is then excited with a low frequency ( 60 Hertz) sinewave. A line will appear on the target corresponding to the angle swept by the peak to peak signal, given the target distance. This test results in the conversion factor:

$$
\mathrm{K}_{\theta}=291 \mathrm{microradians} / \mathrm{volt}
$$

This constant along with the element values listed above completely specify the actuator model.

Up to this point, the actuator model has been based on the primary function witnessed in the transducer's input impedance response, neglecting any secondary effects. This 
is known as the fundamental vibrational mode. However, when piezoelectrics are driven by forcing functions with frequency components greater than the fundamental resonant frequency, other modes of vibration can occur. Therefore, a higher order model must be discussed, taking into account this phenomenon.

The multiple vibrational modes are a result of the shape of the transducer. In the case of the long, thin bar, they can be thought of as multiple folds occurring along the bar. Although many different modes can occur, their effects become less visible at high frequency due to decreased response. For most actuator applications, the secondary resonance need only be recognized.

Effects of the second vibrational mode may or may not be seen in the input impedance transform when reproduced with a spectrum analyzer. In this specific actuator, no definite peaks or valleys were observed. However, striking evidence of this occurence may be witnessed in the angular displacement. This supports the model of Figure 8 .

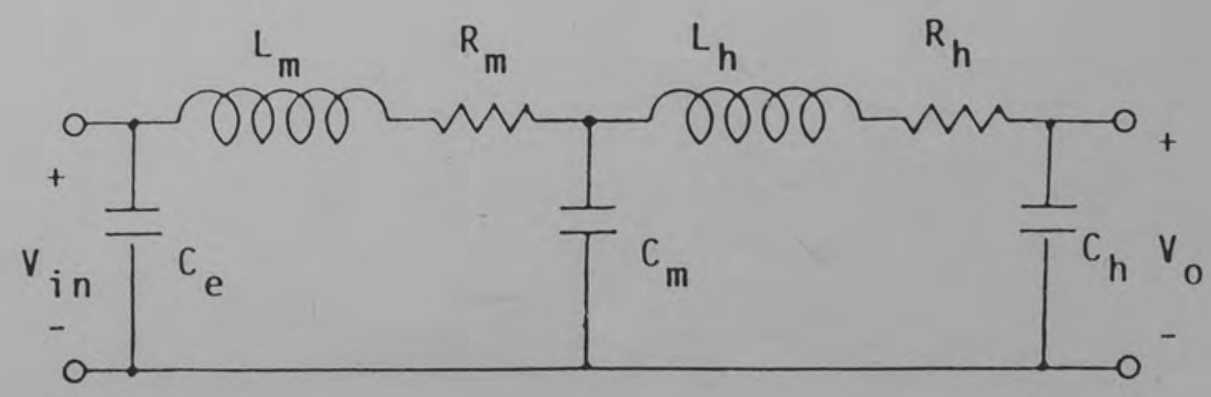

Figure 8. Higher order Model Schematic 
The values $R_{h}$ and $L_{h}$ are chosen much larger than $R_{m}$ and $L_{m}$. This decouples the final RLC series element from an impedance viewpoint, while allowing another resonance to occur in the voltage gain or displacement response. Furthermore, these values can be adjusted to match both the impedance and displacement curves exactly.

Since no secondary resonance effects have been noticed in the prototype's input impedance function, the higher order model can be completely decoupled. This would allow $\mathrm{Z}$ (s) to remain unchanged. $\mathrm{H}_{\mathrm{a}}(\mathrm{s})$ is now cascaded by another second order low pass factor. Owing to the lack of alternate measuring techniques, this additional factor, or the need for it, will not be determined until the system is configured with its position sensors.

The next part of the scanning mirror system to be designed is the direct current amplifier. The high voltage Operational Amplifier (OP AMP) PA08 from Apex Microtechnology has been chosen for a number of reasons, the first of which is $+/-150$ volt supply rails. In addition to its output voltage potential, the PA08 has most of the qualities found in standard general purpose OP AMPs and some extras. These characteristics include high impedance Field Effect Transistor (FET) inputs, low offset voltage, large slew rate and adequate power bandwidth. One of its distinctive features is a large phase margin, making it capable of driving capacitive loads; power dissipation 
limits these loads to approximately 0.4 microfarads. A list of specifications is given in Table 1.[9]

TABLE 1. PA08 SPECIFICATIONS

$\begin{array}{ll}\text { Parameter } & \text { Typical value } \\ \text { Input Impedance } & 10 \mathrm{E}+11 \mathrm{ohms} \\ \text { Offset Voltage } & 0.5 \mathrm{mV} \\ \text { Output Voltage Swing } & +/-140 \mathrm{~V} \\ \text { Open Loop Gain } & 111 \mathrm{~dB} \\ \text { Gain Bandwidth Product } & 5 \mathrm{MHz} \\ \text { Power Bandwidth } & 90 \mathrm{kHz} \\ \text { Slew Rate } & 30 \mathrm{~V} / \mathrm{microsecond} \\ \text { Phase Margin } & 60 \mathrm{degrees} \\ \text { Supply Voltage } & +/-150 \mathrm{~V} \\ \text { Quiescent current } & 6 \mathrm{~mA} \\ \text { Power dissipation } & 26 \mathrm{Watts}\end{array}$

The OP AMPs will be used in a bridge configuration which doubles the output voltage swing capability. A schematic of the amplifier is given in Figure 9. Since the PA08's power bandwidth is well beyond the expected actuator bandwidth, the amplifier can be completed with its mathematical denotation, a gain constant of $20 \mathrm{~V} / \mathrm{V}$. 


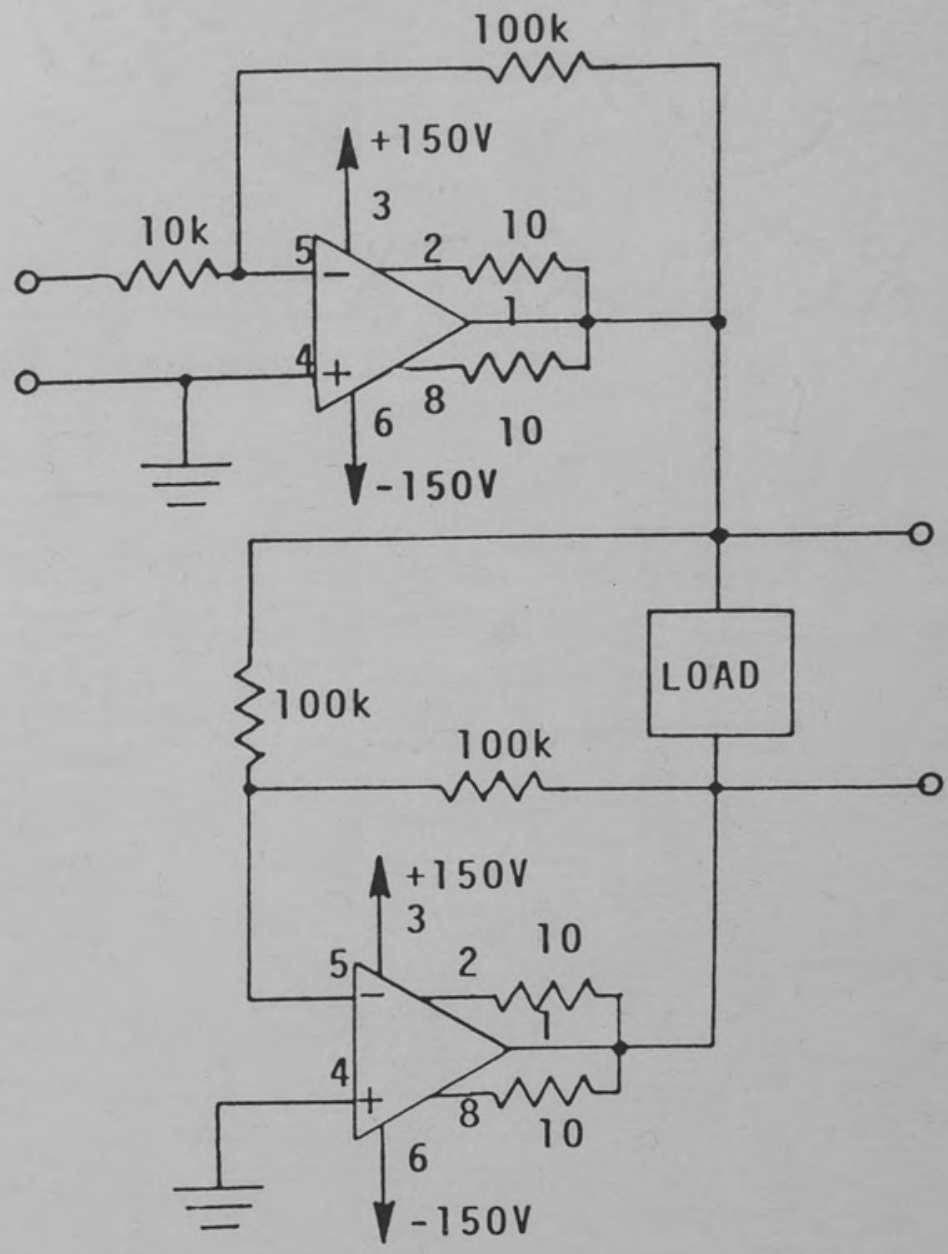

Figure 9. Amplifier Schematic

When developing a simple, efficient means of obtaining rate feedback, it is best to begin with the transfer functions derived for the actuator. The mirror position is described by the function

$$
H_{a}(s)=\frac{K_{\theta}}{L_{m} C_{m} s^{2}+R_{m} C_{m} s+1}
$$


Rate is the derivative of position with respect to time and is shown as

$$
H_{R}(s)=\frac{K_{\theta} s}{L_{m} C_{m} s^{2}+R_{m} C_{m} s+1}
$$

This is the transfer function that must be procured physically. From the synthesis of the actuator model it is understood that position is proportional to charge. It may be deduced that velocity is directly related to the current through the piezoelectric, since current is the derivative of charge over time. However, due to the loading effect of $C_{e}$, the actual input admittance function is

$$
Y(s)=\frac{1}{z(s)}=\frac{\left(C_{e}+C_{m}\right) s\left[\frac{L_{m} C_{e} C_{m} s^{2}}{\left(C_{e}+C_{m}\right)}+\frac{R_{m} C_{e} C_{m} s}{\left(C_{e}+C_{m}\right)}+1\right]}{L_{m} C_{m} s^{2}+R_{m} C_{m} s+1}
$$

What is actually desired for the feedback is the current through the RLC series element of the model or

$$
\mathrm{Y}_{\mathrm{RLC}}(\mathrm{s})=\frac{\mathrm{C}_{\mathrm{m}} \mathrm{s}}{\mathrm{L}_{\mathrm{m}} \mathrm{C}_{\mathrm{m}} \mathrm{s}^{2}+\mathrm{R}_{\mathrm{m}} \mathrm{C}_{\mathrm{m}} \mathrm{s}+1}
$$

However, it is not physically possible to measure this current.

The correct function can be contrived from the actuator current or admittance using pole-zero cancellation. This 
method involves the cascading of $\mathrm{Y}(\mathrm{s})$ with a low pass filter whose characteristics exactly match those of the complex zero pair in $\mathrm{Y}(\mathrm{s})$, so that the result is

$$
\begin{aligned}
& Y^{\prime}(s)=\frac{\left(C_{e}+C_{m}\right) s}{L_{m} C_{m} s^{2}+R_{m} C_{m} s+1} \text { or } \\
& Y^{\prime}(s)=Y_{R L C}(s) \frac{\left(C_{e}+C_{m}\right)}{C_{m}}
\end{aligned}
$$

The final rate transform is

$$
H_{R}(s)=\frac{K_{\theta}\left(C_{e}+C_{m}\right) s}{\left(L_{m} C_{m} s^{2}+R_{m} C_{m} s+1\right)}
$$

The above function will be realized by placing a small sense resistor in series with the actuator. The voltage across this resistor corresponds to $Y(s)$. The low pass function to be cascaded is

$$
H_{L P}(s)=\frac{1}{\frac{L_{m} C_{e} C_{m} s^{2}}{\left(C_{e}+C_{m}\right)}+\frac{R_{m} C_{e} C_{m} s}{\left(C_{e}+C_{m}\right)}}
$$

With the components replaced with their values, the function becomes

$$
\mathrm{H}_{\mathrm{LP}}(\mathrm{s})=\frac{1}{\frac{\mathrm{s}^{2}}{(1263)^{2}}+\frac{\mathrm{s}}{8.8(1263)}+1}
$$


This function is implemented via a Sallen-Key active filter, shown in Figure 10. The design procedure is as follows: [3]

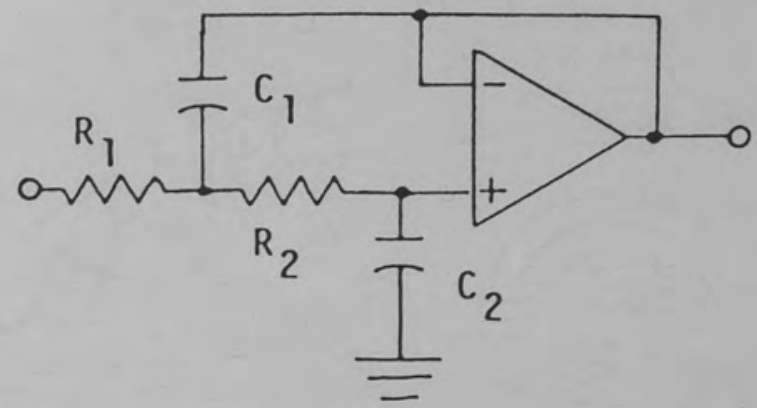

F-gure 10. Low Pass Filter

$$
\begin{aligned}
& \mathrm{c}_{0}=8.0 \mathrm{nF} \\
& \mathrm{C}_{1}>2(8.8) \mathrm{C}_{0} \Rightarrow 150 \mathrm{nF} \\
& \mathrm{C}_{2}<\mathrm{c}_{0} /[2(8.8)] \Rightarrow 330 \mathrm{pF} \\
& \mathrm{b}=\mathrm{c}_{1} 1 / 2 /\left[2(8.8) \mathrm{C}_{2}{ }^{1 / 2}\right]=1.211 \\
& \mathrm{R}_{1}=\left[\mathrm{b}-\left(\mathrm{b}^{2}-1\right)^{1 / 2}\right] /\left[1263\left(\mathrm{C}_{1} \mathrm{c}_{2}\right)^{1 / 2}\right]=59.3 \mathrm{k} \text { ohms } \\
& \mathrm{R}_{2}=\left[\mathrm{b}+\left(\mathrm{b}^{2}-1\right)^{1 / 2}\right] /\left[1263\left(\mathrm{C}_{1} \mathrm{c}_{2}\right)^{1 / 2}\right]=213.7 \mathrm{k} \text { ohms }
\end{aligned}
$$

Low tolerance components ( $1 \%$ resistors, $5 \%$ capacitors) are chosen due to the high quality factor. A schematic of the final rate feedback electronics is given in Figure 11.

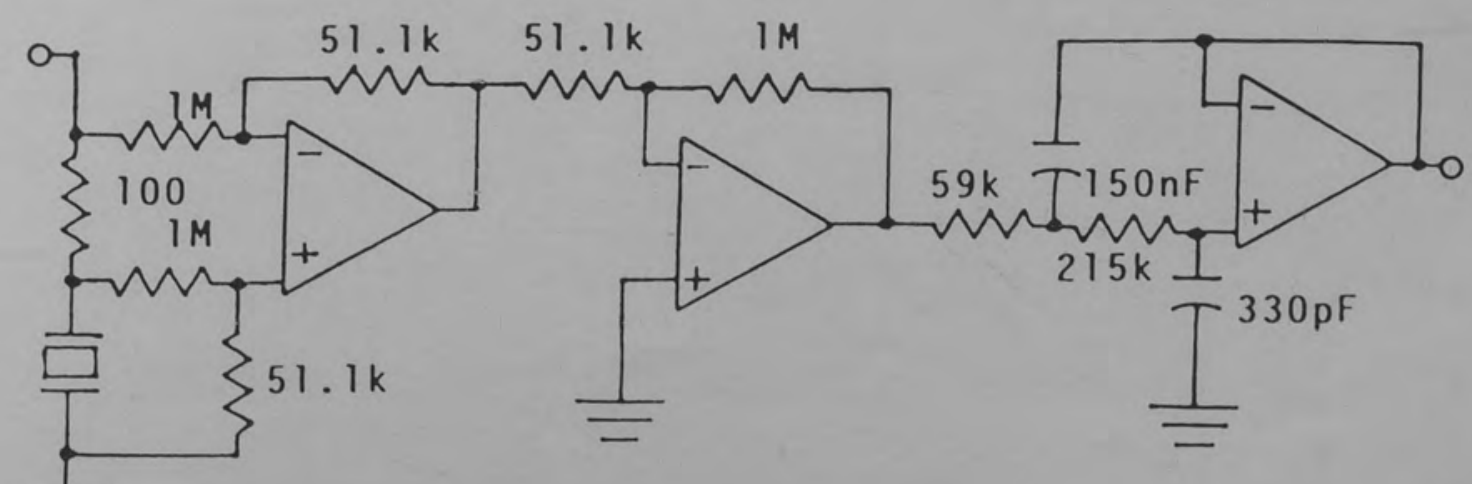

Figure 11. Rate Feedback Electronics 
The final subsystem model yet to be described is the position sensor or proximity detector. The term proximity is used to indicate that there are no direct mechanical linkages used to measure with, differentiating it from a shaft resolver or potentiometer. Although there are a variety of other means of proximity detection, such as laser quadrant detectors, infrared and ultrasonic receivers, the method chosen (for simplicity and sensitivity) uses the Eddy current phenomenon.

This effect begins with the magnetic field created by an inductive circuit. Materials placed within this field can be modeled as elements in series or parallel with the inductor. The most familiar occurrence is the use of iron/ferrite cores for inductors to increase their value. When a conductor is placed in the field, it can be modelea as a parallel resistance. This parallel "Eddy" current path is normally used to describe the dissipation losses in transformers. In the detector application, the resistance decreases as proximity between the conductor and inductor increases. This function is nonlinear and can be related to the solid angle of the conductive target viewed from the point where the field lines converge. As the target gets close to this point, the resistance increases in geometric proportions.

The next issue at hand is to decide upon a sensitive means to measure this phenomenon. A common circuit that is 
both facile and extremely sensitive is a sinusoidal oscillator. It requires an open loop gain of exactly one at exactly 180 degrees of phase shift in order to remain oscillating in a bounded fashion. This type of circuit contains two components, a bandpass filter with a high quality factor and a nonlinear element whose gain is dependent upon output amplitude. The FET Colpitts oscillator of Figure 12 possesses both of these. The frequency of oscillation is set by the center frequency and quality factor of the bandpass filter made up of the passive elements. The amplitude of oscillation is determined by the FET's transconductive response, the DC bias point and the passive filter's midband gain.

The Eddy current effect is manifested as a decrease in oscillation amplitude with increased proximity. This can best be explained using Figure 13. The curve illustrates the FET transconductance. The two load lines indicate the filter's resonant response at extreme proximities. When the conductive target is far from the inductor, the resistance due to proximity is large and has no effect on filter gain, allowing the oscillator to reach its maximum amplitude. When the target is in close, the proximity resistance reduces the filter gain and decreases the amplitude.

Finally, the nonlinearity problem must be dealt with. Due to the nature of the phenomenon and the square law FET response, the position detector output will increase by 
leaps and bounds. This exponential response can be leveled off using a differential approach in the same manner as a Wheatstone bridge. Two oscillators can be used with their inductors placed on opposite sides of the mirror. The electrodes on the piezoelectric transducers will make excellent conductive targets. The oscillation frequencies of the two circuits should be placed approximately $100 \mathrm{kHz}$ apart to avoid the occurence of difference (beat) frequency noise. The amplitudes of the two signals are then rectified and filtered so that the difference of two DC voltages can be taken. As the mirror moves, the differential output tracks the motion linearly. The schematic of the position detector is shown in Figure 14. The scale factor for the detector has been calibrated using the same technique as in the actuator. This scale factor is given as

$$
\mathrm{K}_{\mathrm{pd}}=172 \text { Volts } / \text { radian }
$$

with less than 18 linearity deviation over its entire range.

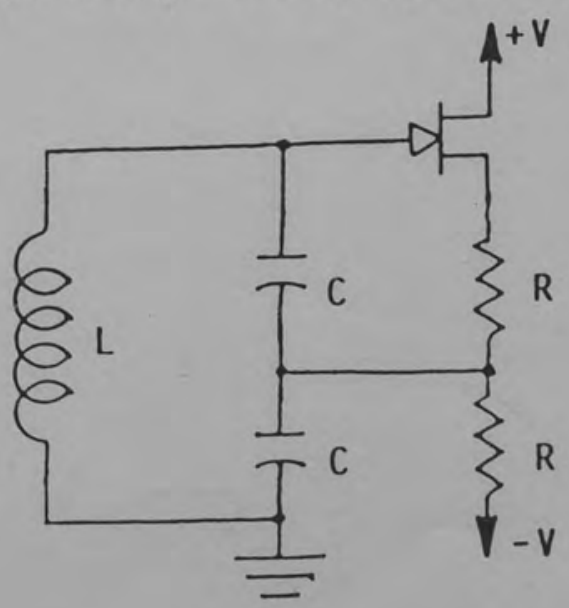

Figure 12. Colpitts Oscillator 


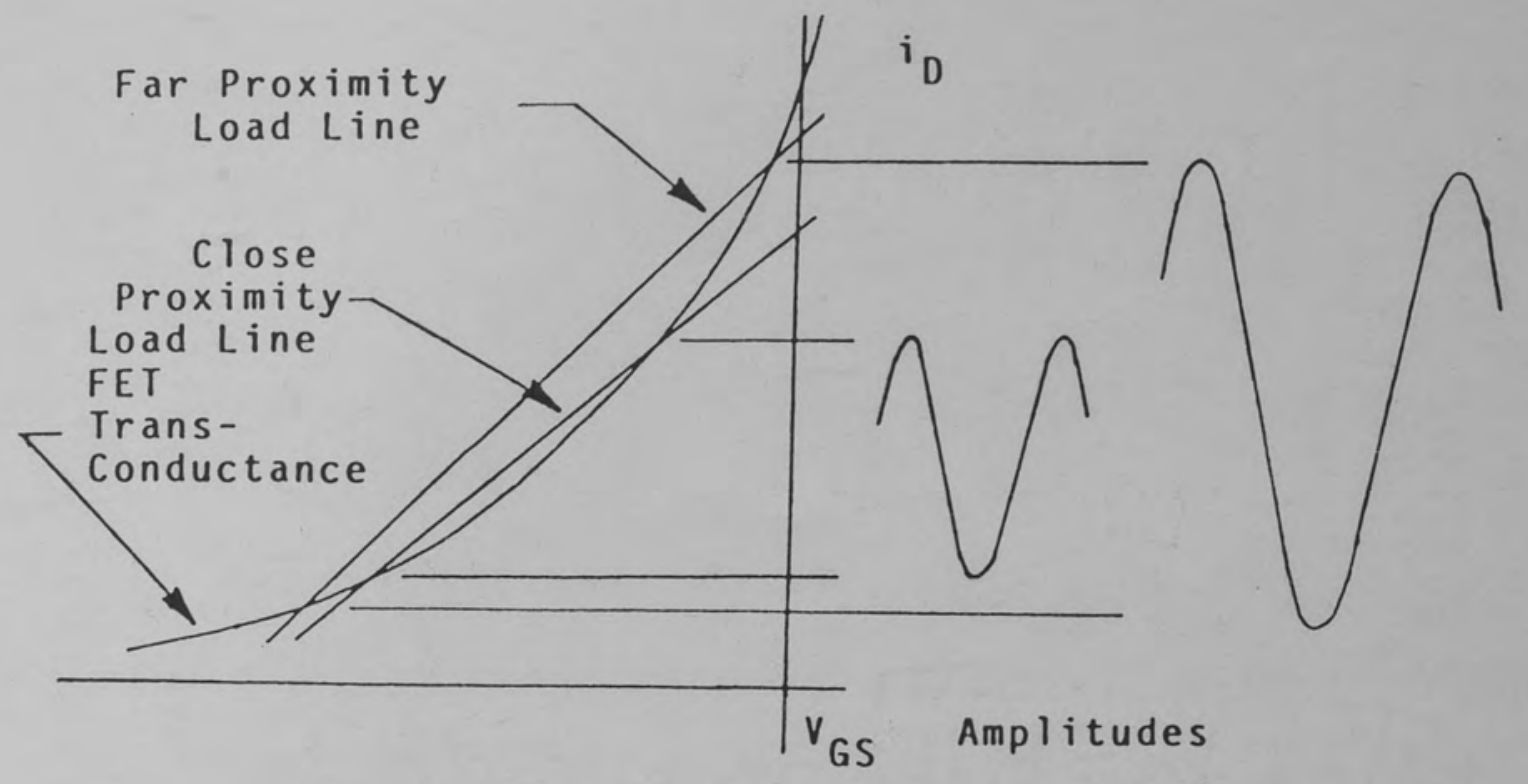

Figure 13. Oscillator Amplitude

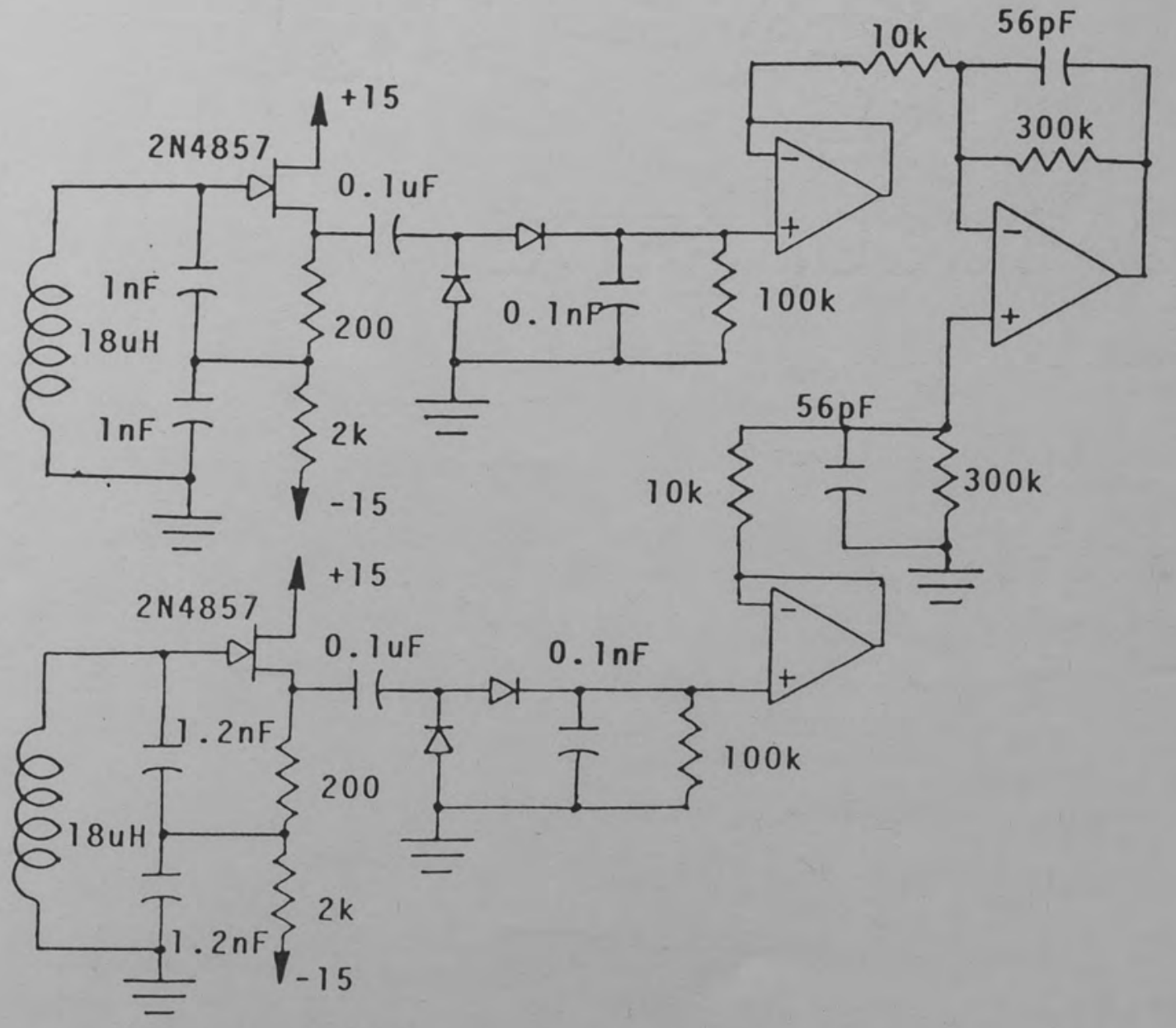

Figure 14. Position Detector Schematic 


\section{SYSTEM SYNTHESIS AND ANALYSIS}

Now that all of the subsystem models have been defined, the scanning mirror system design can be completed. The design procedure is as follows:

1. Definition of operating requirements

2. Formation of system structure

3. Verification of plant model

4. Design of compensation electronics

5. Comparison of prototype to model with respect to system requirements

At the heart of any system is a set of absolute requirements which state what the hardware must be able to do. Since the intent of this thesis is to show piezoelectric actuators' potential, the requirements will be chosen to best illustrate actuator performance without adding complexity, which tends to cloud the issue. These specifications are listed below:

* Static position accuracy - $10 \%$

* Closed position loop bandwidth $-300 \mathrm{~Hz}$

* Open position loop gain margin - lodB

* Open position loop phase margin - 25 degrees

Immediately, the bandwidth, gain margin and phase margin indicate that the structure of the system will be represented in the steady state frequency domain. In this 
domain, the system is shown as a block diagram, with each block containing the Laplace transform of the function being implemented. The actual performance of the prototype can be measured and compared to the requirements directly. Although the steady state frequency domain is not $\bar{c}$ physical domain like time, the frequency domain does completely specify the system's time response in the linear regic.. Bandwidth and relative stability determine how fast the sistem will react to a stimulus and how much time it will take to settle to the indicated position. [8]

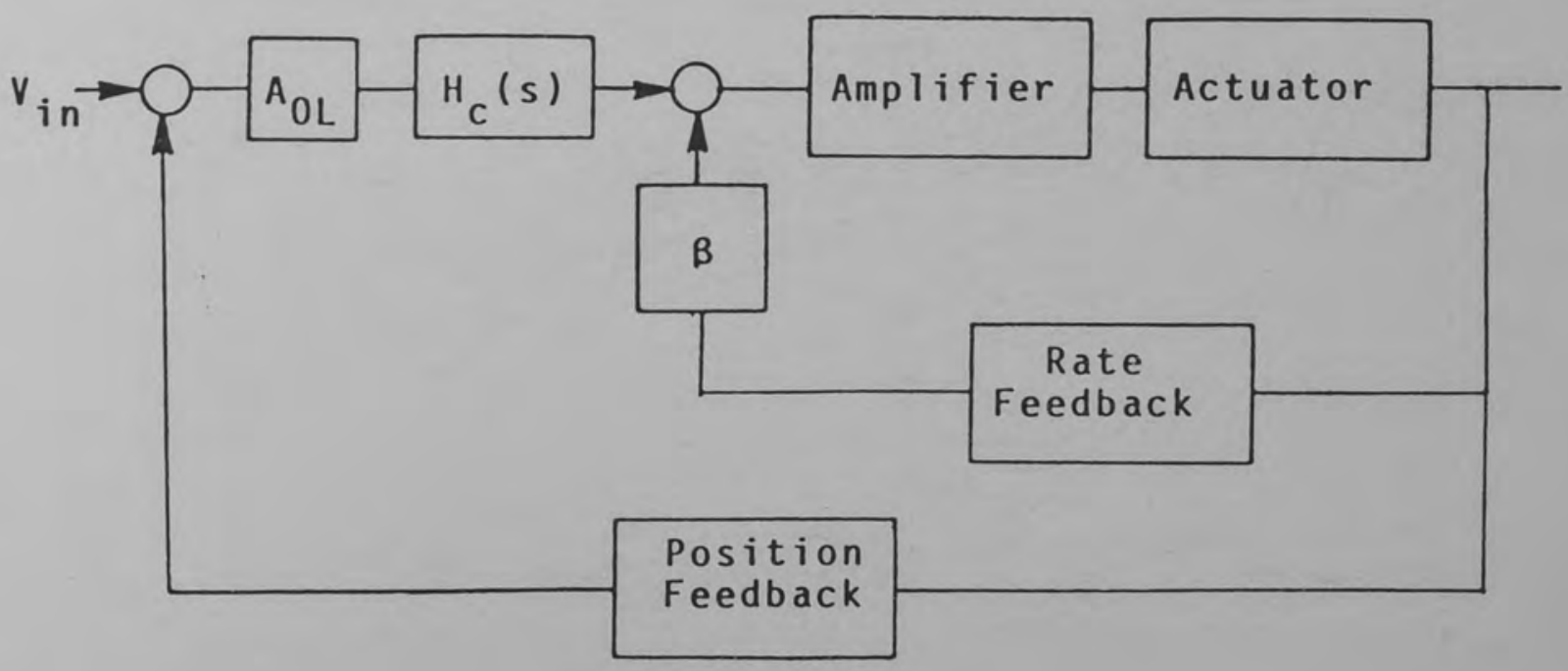

Figure 15. Block Diagram

To arrive at the block diagram of Figure 15, it is first noted that there are two feedback variables, rate and position, and therefore two feedback loops and two compensation blocks. The control constant $\mathrm{A}_{\mathrm{OL}}$ will be chosen for accuracy and $\boldsymbol{\beta}$ for relative stability. 
The compensation filter $\mathrm{H}_{\mathrm{C}}(\mathrm{s})$ is intended to correct any higher order differences between the prototype and the second order model of the actuator. This filter presents the need for the third step in the design procedure, plant model verification. This is done by comparing the frequency response of the prototype with that of the model. The plot of Figure 16 shows a distinct difference between the model and the prototype. Peaking occurs in the hardware magnitude response at approximately $1 \mathrm{kHz}$. This resonance is due to the second vibrational mode of the piezoelectric benders, thus proving the need for the higher order model. The Laplace representation of the actuator can be updated by adding a cascaded low pass filter, whose characteristics match that of the newly found resonance. These parameters have been extracted from the plot and are shown in the updated equation

$$
H_{a}(s)=\frac{K_{\theta}}{\left[\frac{s^{2}}{(1131)^{2}}+\frac{2(.063)}{1131}+1\right]\left[\frac{s^{2}}{(6283)^{2}}+\frac{2(.031) s}{6283}+1\right]}
$$

This new model compares favorably with the measured response, as shown in Figure 17.

Now that the model has been accurately identified, the next effort in the procedure is to design the compensation blocks. The values $A_{O L}, \beta$, and $H_{C}(s)$ flow directly from the operating requirements. Closed loop accuracy equal to a 


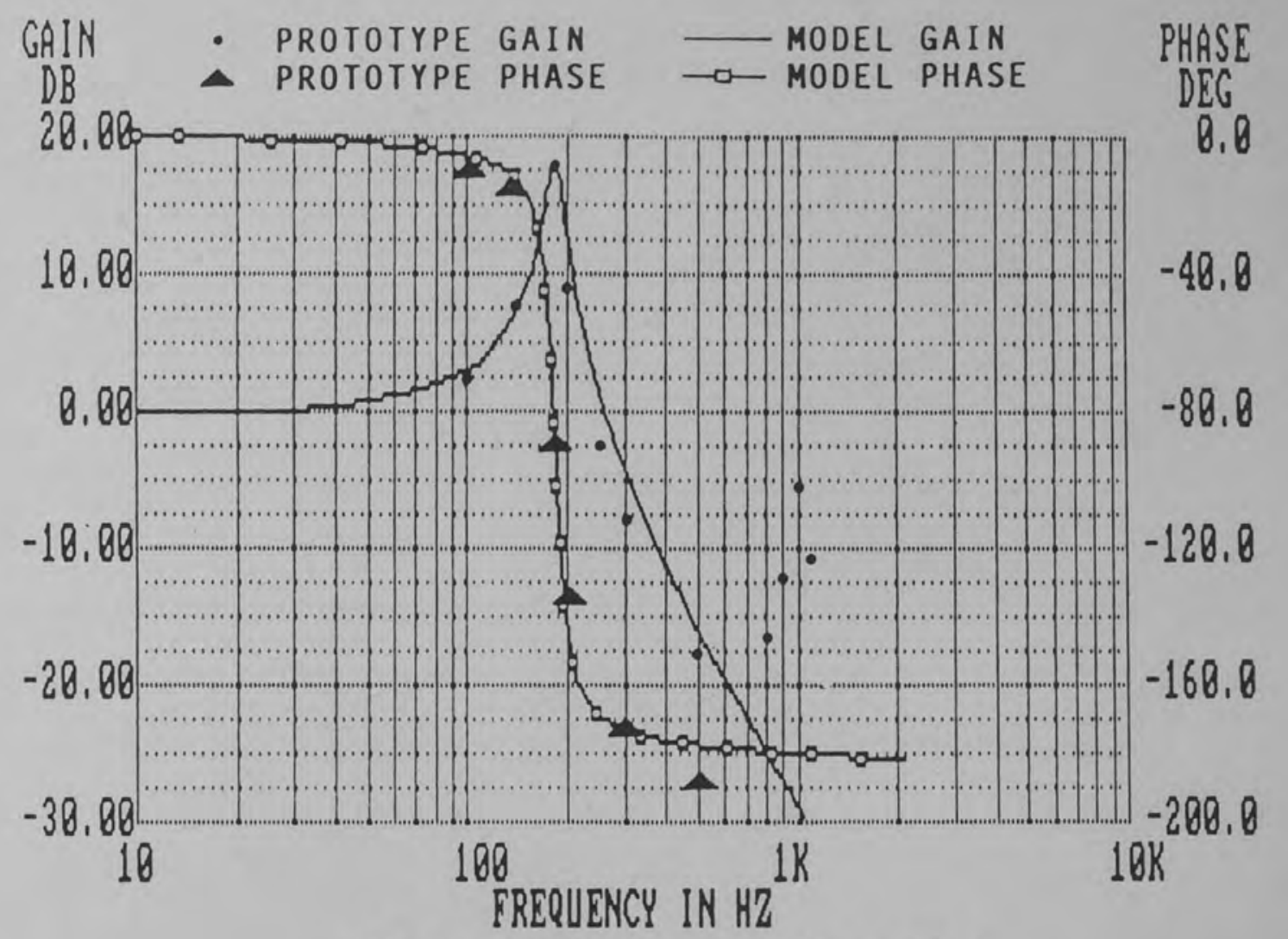

Figure 16. Actuator Response

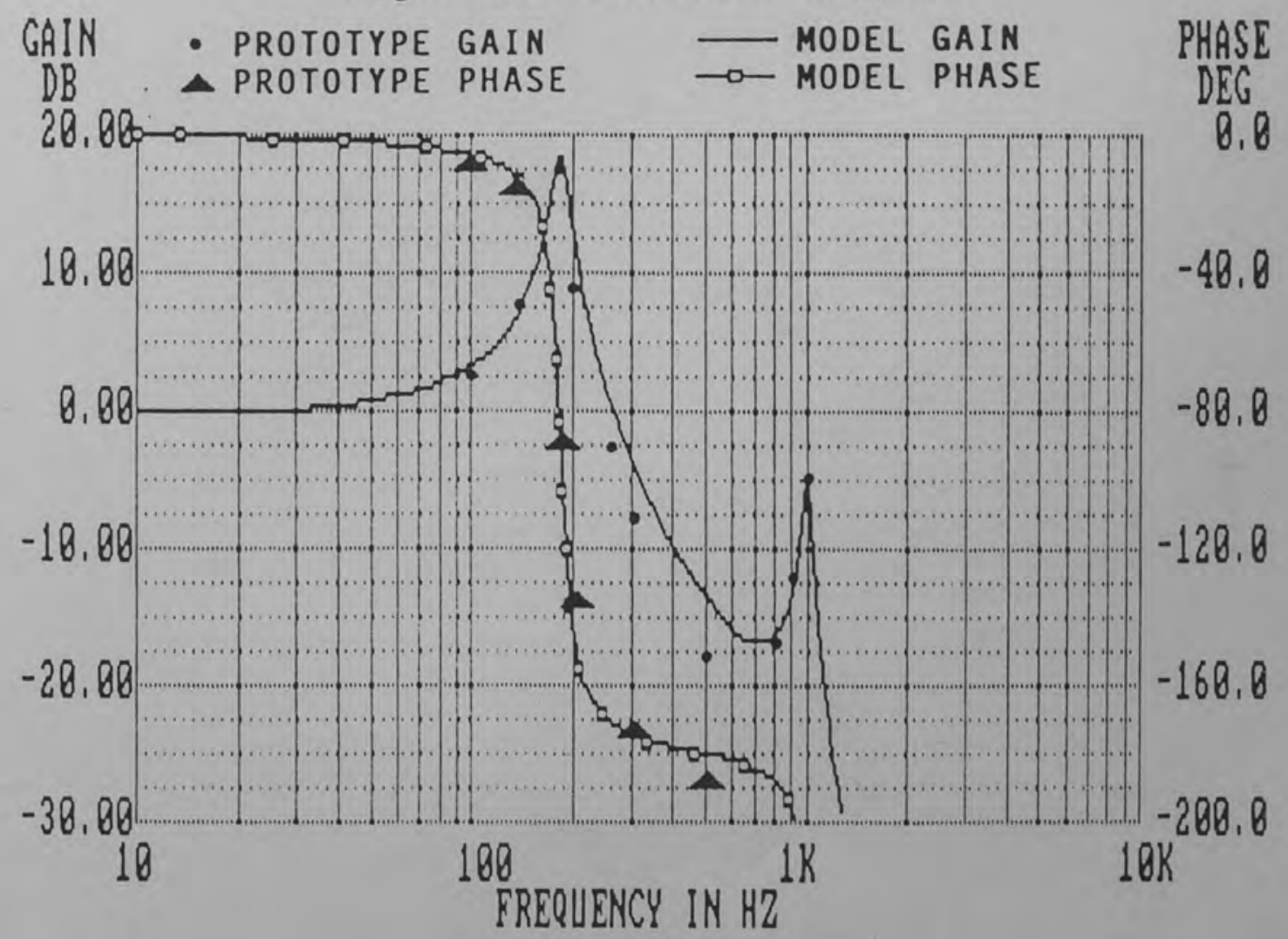

Figure 17. Updated Actuator Response 
nonzero constant implies that the system is classified as "type zero" or no free integrations. This means that the accuracy is strictly a function of open loop gain. Using the equation

$$
A_{C L}=\frac{A_{O L}}{\left(1+A_{O L}\right)}
$$

it is evident trat an accuracy of $10 \%$ requires the loop gain $\mathrm{A}_{\mathrm{OL}}$ to be greater than or equal to 9 .

Increased bandwidth is also a function of loop gain. In the equation above, where $\mathrm{A}_{\mathrm{OL}}$ is replaced with a low pass filter having the same gain, the resulting closed loop "break" frequency follows the relation

$\mathrm{W}_{C L}=\mathrm{W}_{\mathrm{OL}}\left(1+\mathrm{A}_{\mathrm{OL}}\right)^{1 / 2}$

To cover the increase from the actuator bandwidth of $180 \mathrm{~Hz}$ to $300 \mathrm{~Hz}$, a ioop gain of at least 2 is required. To meet both the accuracy and bandwidth specifications, $\mathrm{A}_{\mathrm{OL}}$ is chosen to be $10 \mathrm{~V} / \mathrm{V}$.

The last two requirements place margins on the relative stability of the system. Before even thinking of stability, the actuator resonances must be brought under control. Although the intent of the rate loop is to damp the primary vibrational mode, it will not provide any help with the secondary. Therefore $\mathrm{H}_{C}(\mathrm{~s})$ will be used for that purpose. 
A band-reject or "notch" filter will provide the needec. attenuation of the actuator's $1 \mathrm{kHz}$ resonance. The equatior. to be implemented is

$$
H_{C}(s)=\frac{\left.\frac{s^{2}}{(6283}\right)^{+1}}{\frac{s^{2}}{(6283)^{2}}+\frac{2 s}{(6283)}+1}
$$

The biquad active filter of Figure 18 adequately realizes $\mathrm{H}_{\mathrm{C}}(\mathrm{s})$. This filter is composed of a unity gaif: bandpass filter, whose denominator matches that of $\mathrm{H}_{\mathrm{C}}(\mathrm{s})$ subtracted from the input. The result is

$$
H_{C}(s)=1-\frac{\frac{2 s}{(6283)}}{\frac{s^{2}}{(6283)^{2}}+\frac{2 s}{(6283)}+1}
$$

which is indeed equal to the previous equation. [3]

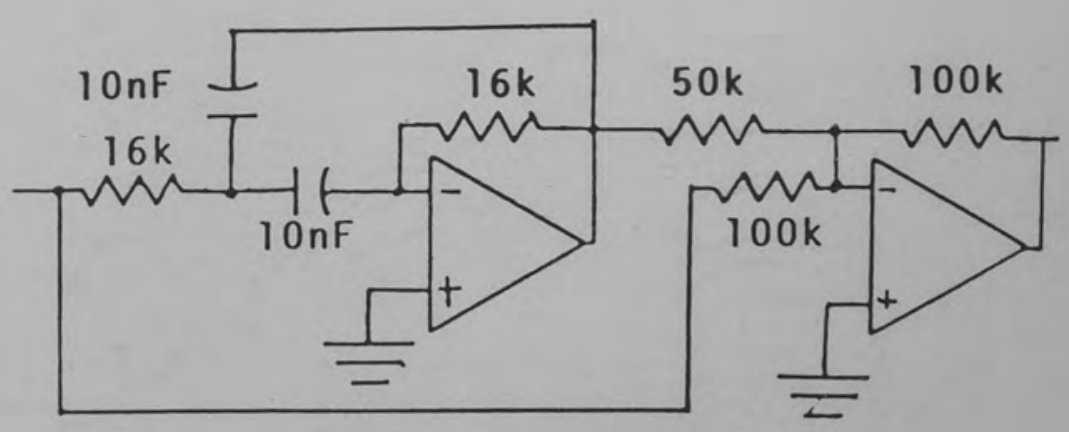

\section{Figure 18. Biquad Notch Filter}

Now that $\mathrm{A}_{\mathrm{OL}}$ and $\mathrm{H}_{\mathrm{C}}(\mathrm{s})$ have been determined, the value B will be chosen to dampen the actuator's primary resonance enough to meet the required gain and phase margins. This damping effect of $\beta$ can be illustrated with the closed loop 
rate transfer function. If the developed rate equation $\mathrm{H}_{\mathrm{R}}(\mathrm{s})$ is used, neglecting the transducer's higher order terms, the resulting closed loop transfer function is

$$
\mathrm{H}_{\mathrm{CR}}(\mathrm{s})=\frac{1}{\frac{\mathrm{s}^{2}+{ }^{2}\left[\frac{2(.063)+20 \beta]}{(131)^{2}}+1\right.}{(1131)}+1}
$$

In this approximation, the damping is increased as the feedback gain $B$ is increased. The higher order terms limit the amount of gain that can be added while maintaining stability. However, due to the sharp cutoff nature of the bandpass response, stability will not be a problem.

To pass the gain margin and phase margin requirements, the closed loop response should have a damping ratio of 2.75. This corresponds to a $B$ of 0.269 .

Since all of the control parameters have been chosen, the system design is now completed. The schematic is shown in Figure 19. A final block diagram of the scanning mirror system is given in Figure 20. Figures 21 and 22 are the open and closed position loop responses, respectively. A list of pertinent data has been compiled in Table 2 . 
TABLE 2. PERFORMANCE DATA

$\begin{array}{lc}\text { Parameter } & \text { Value } \\ \text { Static position loop accuracy } & 9.09 \% \\ \text { Closed loop bandwidth } & 380 \mathrm{~Hz} \\ \text { Gain Margin } & 10.4 \mathrm{~dB} \\ \text { Phase Margin } & 30^{\circ} \\ \text { Maximum Deflection } & \pm 4.5^{\circ} \\ \text { Maximum Slew Rate } & 0.890 / \mathrm{ms} \\ \text { Delay Time } & 3.2 \mathrm{~ms} \\ \text { Settling Time } & 6.0 \mathrm{~ms}\end{array}$

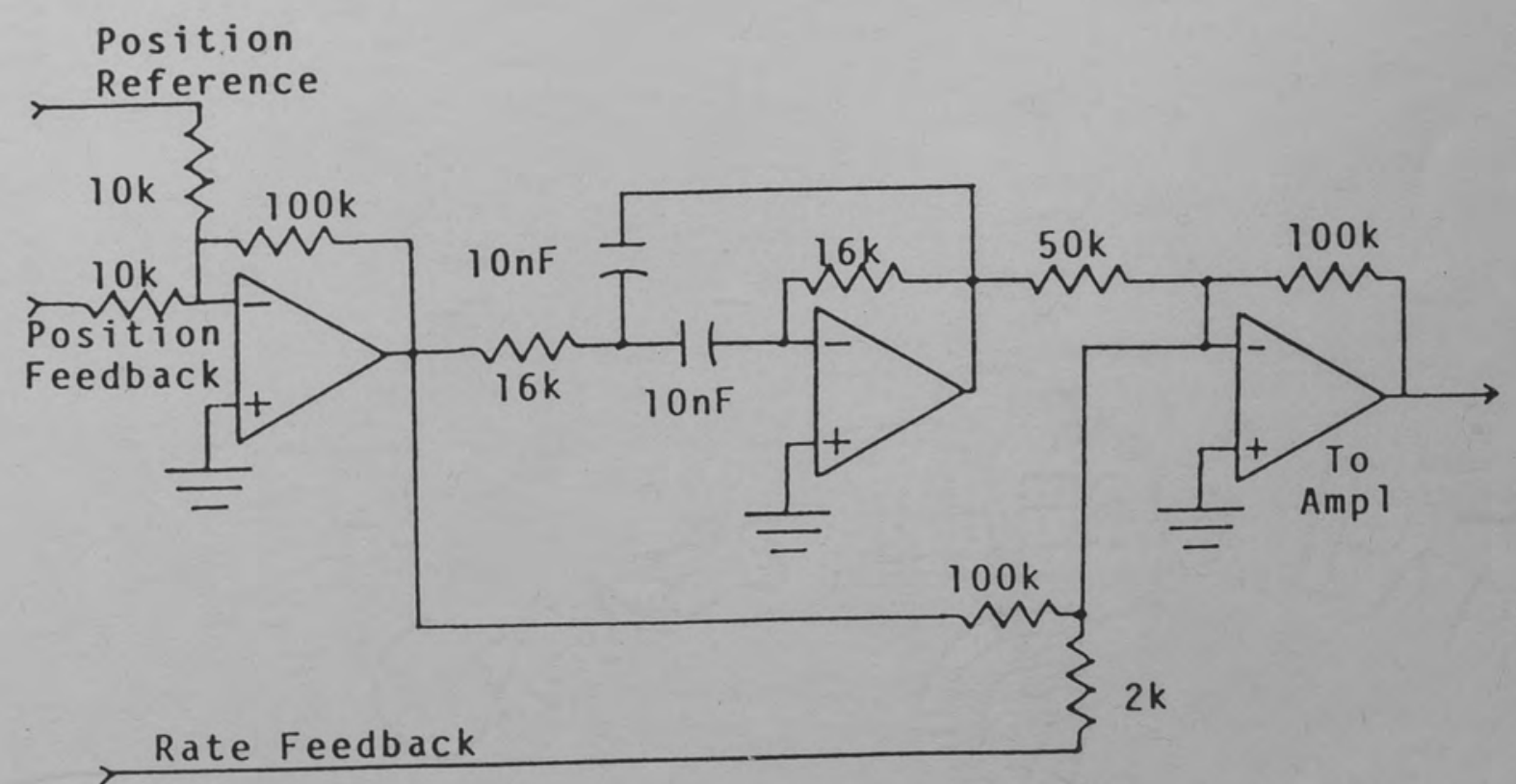

Figure 19. Control Schematic 


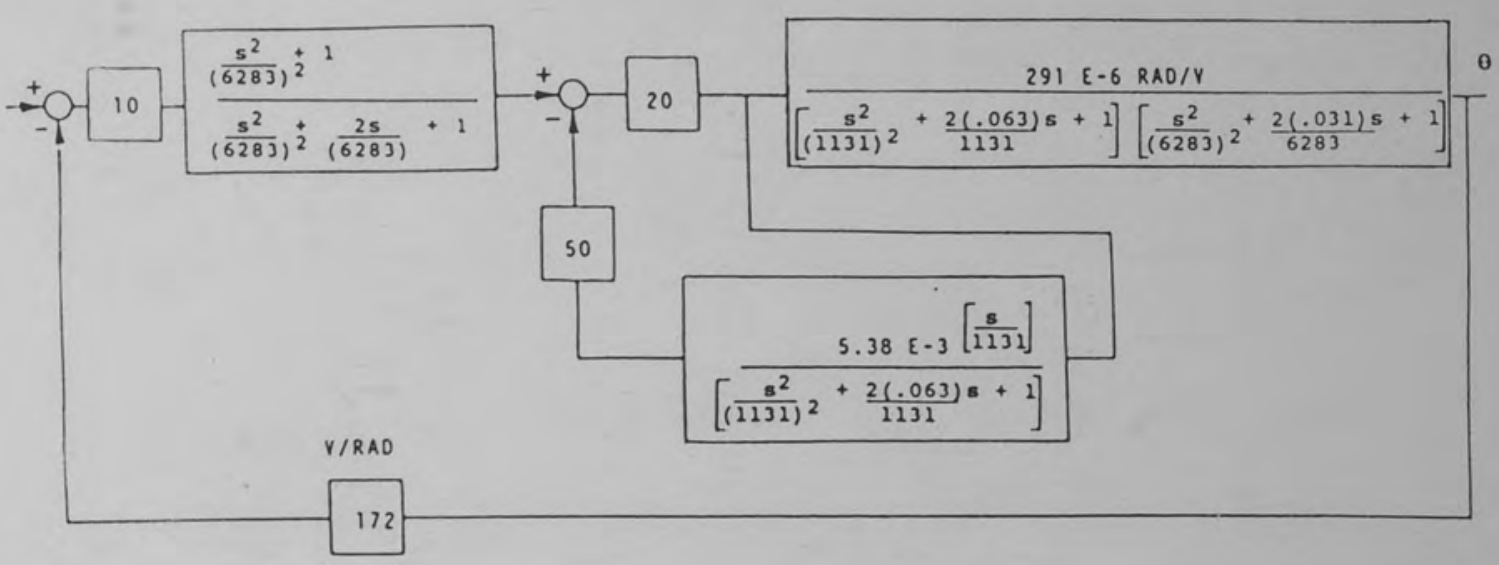

Figure 20. System Block Diagram

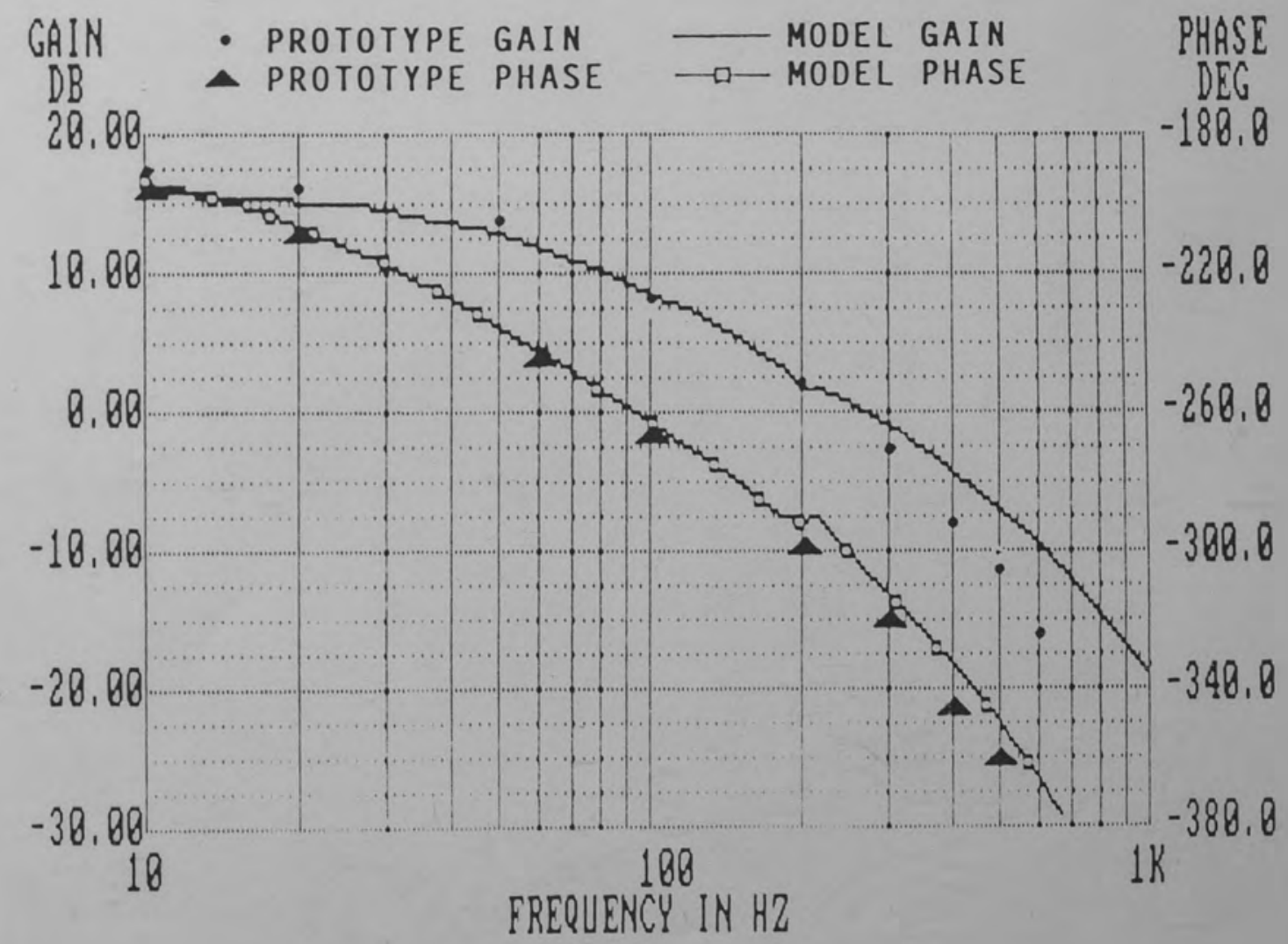

Figure 21. Open Position Loop Response 


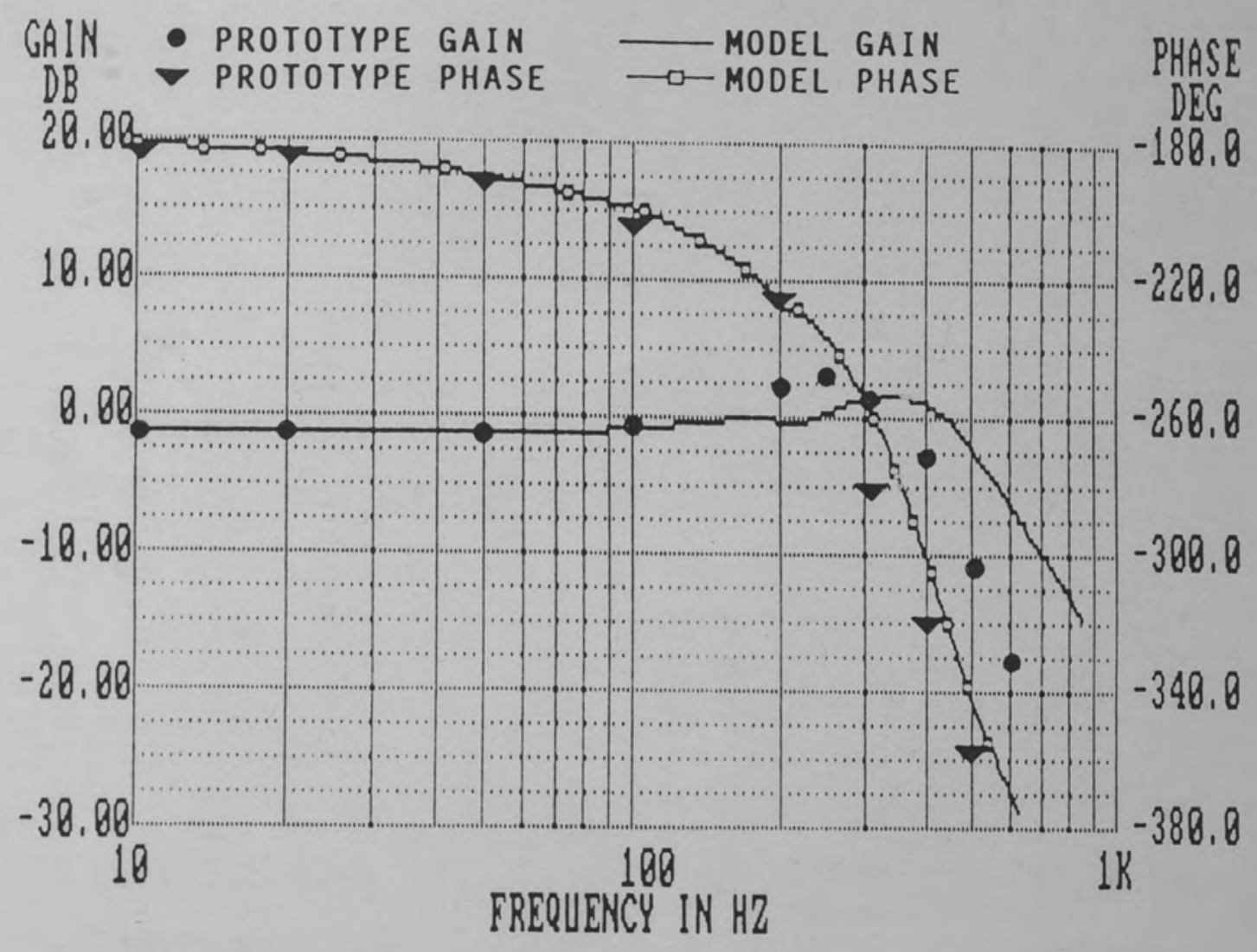

Figure 22. Closed Position Loop Response 


\section{CONCLUSIONS}

The first conclusion to be made from the performance data is that the system has met its requirements of accuracy, bandwidth and stability. Furthermore, there is correlation with the model and prototype open and closed loop frequency responses. One descrepancy occurred, howeve: Both responses of the prototype seem to roll off before the those of the model. This is due to an antiresonance in the actuator occurring at $720 \mathrm{~Hz}$, which can be attributed to an absorption of energy by the adhesive hinge. The notch can be considered an extra bonus; it gives the opportunity to introduce lead compensation into the position loop, which would in turn increase bandwidth. It does not: pose any concern to the system at present.

The other large signal parameters are useful in evaluating the system performance. The most outstanding of these is the maximum deflection obtained. This large scan angle widens the range of applications conventionally considered for piezoactuators. Note that this value can be increased further by increasing the amplifier's output swing .

The slew rate limit indicates the maximum speed the mirror is capable of. Although this value is adequate for some applications, it can also be increased. One simple 
solution is to provide more dynamic range, ie. a voltage amplifier with larger supply rails. However, even more can be improved. A trade-off exists between maximum deflection and speed or bandwidth. Smaller piezoelectric transducers made of stiffer, less sensitive material will operate over larger bandwidths with a decrease in scan angle. This tradeoff can be optimized when designing the piezoactuator for a specific application.

The time delay is a measure of the sum total of phase lags occuring within the loop and is primarily a result of the linear response. This number can increase slightly with large signals due to slew rate limiting. Settling time, on the other hand, can vary tremendously with nonlinearities which cause limit cycling. Since no large increases in settling time were observed, it can be said that the results of system nonlinearities did not adversely affect its performance.

It is evident that this piezoelectric scanning system would operate well in a beam scanning application. With minor modifications, it can operate over two degrees of freedom, making it an excellent beam steering system. Applications of this type include heavy duty laser engraving, laser autoalignment and target tracking and designation. The hinges coupling the mirror to the transducers would be replaced with pin contacts. Two transducers would be attached to the remaining two sides of 
the mirror, forming a cross. Duplicate sets of electronics can be used for elevation and azimuth control. Careful placement of the position sensors would provide decoupling of the two axes. Also, non-orthogonal axis techniques might be implemented reducing the number of transducers needed to three

Although the $300 \mathrm{~Hz}$ bandwidth of the prototype is somewhat restrictive in imaging applications, there is much room for improvement Using the trade-off discussed, bandwidths equal to those achieved by acoustic bender resonators $(5-20 \mathrm{kHz})$ are possible. 


\section{SUMMARY}

Pusher and bender piezoelectric transducers have been discussed, showing both their normal applications and their possible use as an actuator. The bender was chosen for the transducer type due to its increased mechanical advantage.

The advantages found in piezoactuators over their conventional motor counterparts were in the areas of reliability, efficiency, linearity and cost. The disadvantages were low motion sensitivity, resonances and hysteresis. A system was proposed that would overcome these difficulties, while benefitting from the advantages.

Models for each part of the system have been developed, beginning with the actuator. A dual cantilevered bimorph design has been presented, which maximizes the amount of angular deflection possible. Its electromechanical function was expressed as a circuit, whose values were based on an empirical modeling technique. The amplifier chosen to drive the actuator was shown to have adequate bandwidth and output voltage swing. Two power OP AMPs were used in a bridge configuration.

Rate sensing has been used to dampen the actuator's fundamental resonance. The rate loop feedback has been uniquely derived using the current from the transducer. 
Pole-zero cancellation provided the final rate transfer function desired.

The final subsystem, the position sensor provides a bandwidth increase while removing hysteresis effects. It has been designed using the effects of Eddy currents due to conductor proximity. A dual oscillator approach was used which provided the linearity and sensitivity required.

The second order model of the actuator was not adequate enough to insure stability, so it was updated to include the second vibrational mode resonance. This updated model correlated favorably with the plant's measured response.

System requirements were defined so as to present a complete design procedure. The system control parameters such as loop gain and compensation were chosen to meet system requirements.

Performance data from the prototype met the system requirements and matched the model response. other time domain parameters were also identified in order to further illustrate the system's capabilities. This performance shows that piezoelectric actuators do have potential for many movable mirror applications. There is room for research in bandwidth-deflection optimization. Also, a two axis transducer system using the cross approach discussed could be further developed. 


\section{REFERENCES}

[1] Baddiley, C.J., "Image Scanning Systems Using Tilting Plane Mirrors", Infrared Physics, Volume 17, London: Pergamon Press, 1977.

[2] Beer, Ferdinand and Johnstor, E. Russell Jr., Mechanics of Materials, New York McGraw Hill, 1981, pp. 234-255.

[3] Daryanani, Gobind, Principles of Active Network Synthesis and Design. New York: John Wiley and Sons, 1976, pp. 269-283; 339-344.

[4] Edo Corporation, Salt Lake City, Utah. "Custom Piezoelectric Transducer Design Catalog."

[5] McElroy, J.H. , "Laser Tuners Using Circular Piezoelectric Benders", Applied Optics, Volume 14, No. 6, New York: American Institute of Physics, 1975 .

[6] Martin, Robert James, Analysis and Synthesis of Active Feedback Applied to Piezoelectric Devices. orlando, Florida: By the Author, 1984.

[7] Micro-CapII Microcomputer Circuit Analysis Program, Sunnyvale, Ca.: Spectrum Software, 1985.

[8] Melsa, James L. and Schultz, Donald M., Linear Control Systems, New York: McGraw Hill, 1969, pp. 185-244.

[9] Power op Amp Handbook, Tuscon: Apex Microtechnology, 1985 .

[10] Vernitron Piezoelectric Division, Bedford, Ohio. "Ceramic Piezoelectric Transducer Selection Guide." 